\title{
How domestic violence came to be viewed as a public issue and policy object
}

\section{Kathya Araujo}

Researcher of the

Gender and Policies

Programme,

Centre for Studies on

Women's Affairs

Virginia Guzmán

Deputy Director,

Centre for Studies on

Women's Affairs

\section{Amalia Mauro}

Researcher of the Gender and Policies Programme, Centre for Studies on

Women's Affairs

cem@rdc.cl
This article analyses the process whereby domestic violence in Chile became a subject of open discussion and a public issue included in the institutional agenda of the Executive and the Legislature, giving rise to preventive programmes against such violence and public services for aiding its victims, together with the adoption of a law against intra-family violence in 1994. The analysis highlights the dynamic and complex nature of the process, whose course and results were not and could not be determined a priori. Public issues do not exist in their own right, as purely objective phenomena, but are constructed by actors who operate in different settings, exchanging and confronting discourses based on various frames of interpretation. Several different phases may be distinguished in the process, depending on the features and opportunities offered by the political and institutional system, the different types of actors involved, their organizational resources, the structure of the links they establish with each other, and the frame of interpretation that guides what the actors do. Seen from this standpoint, the emergence of cases of violence as a public issue is at the same time the story of the establishment of women as valid social subjects, their organizations, their strategies for mobilizing the issue in different public contexts, and the spread of new types of discourse and proposals on gender-related matters. 


\section{I}

\section{How public issues are constructed}

The construction of public issues is supported and mobilized by different actors who join together around a matter which becomes the centre of their attention, initiatives and discussions and thus turns into an issue in the political domain. The actors recognize each other as being committed to the formulation, defence, negotiation and agreement on a solution for that issue. They enter, leave or remain in place, or change their roles and positions in the course of the process, which extends across various different social and institutional areas.

In an ideal cycle, a policy begins with the recognition of a given experience as a formal issue and problem by different actors who consider it unacceptable. The next step is the formulation of the problem as a public issue, for which it is necessary to define it, to formulate hypotheses on its causes, and to propose possible solutions. The cycle continues with the incorporation of the problem on institutional agendas. ${ }^{1}$

The inclusion of the issue on the institutional agenda makes it necessary to translate it into the corresponding political and institutional logical frameworks before it can give rise to legal instruments, programmes or public services. As Muller and Surel (1998, p. 57) rightly note, "social phenomena pass through a series of prisms which act as selection mechanisms and modify the nature, audience and significance of the perceived phenomena in order to make them a legitimate subject of public action".

According to McAdam, McCarthy and Zald (eds., 1996), social movements are conditioned by the simultaneous influence of the opportunities of-

$\square$ This article is based on the results of the study "The role of social networks in putting domestic violence on the public and institutional agenda" carried out in 1997-1998 by Virginia Guzmán, Kathya Araujo, Amalia Mauro, Vicente Espinoza and Eugenia Hola with the support of the Gender Studies Research Fund of the National Council for Science and Technology (CONICYT).

${ }^{1}$ The implementation of the corresponding law and of the necessary services and departments gives rise to a new stage in which the actors are mainly of an institutional nature and the characteristics of the relations involved are changed. fered by the institutional and political system, the organizational resources and collective dynamics of the actors involved, and the different frames of interpretation that guide their behaviour. These factors interact and mutually strengthen each other, thus facilitating the emergence and subsequent course of social processes.

According to those authors, the opportunities for collective action, like its extent and the form it takes, are structured by the political system. At the same time, formal or informal organizational structures also have a fundamental influence on the extent and form of exchanges of views and discussions among the actors and on the actions the latter take to further the matters that interest them.

The combination of these two dimensions -political opportunities and organizational structuresprovides a structural base for action. However, this base will not be enough unless it is accompanied by deliberate strategic efforts to construct a new shared view of the world, imbued with the conviction that the problem in question can be solved if all those concerned act together. This is how collective action on an experience or social situation considered to be unacceptable is legitimized and motivated.

The new frames of interpretation represented a break with those which sought to explain the situation in the past. In order for them to be accepted, they based themselves both on the existing principles and social values and on more abstract ones. As we shall see below, the interpretation of violence against women as an expression of their lower status in relations between the sexes called for a new frame of interpretation making explicit mention of sex discrimination. The acceptance of domestic violence as a public issue, however, stems from a prior consensus asserting respect for physical integrity and human dignity.

As may readily be supposed, the different interpretative schemes are neither permanent nor based on general agreement: they compete with each other, support or promote conflicts between the actors in a public domain, confirm or challenge the dominant interpretations and suggest alternative courses of action. 
Three phases may be identified in the construction of the issue of domestic violence as a matter for public policy in Chile. The first is the emergence of the process when the country was still under a dictatorship. The second is the formation of the issue by actors coming mainly from civil society. The third is the institutionalization of the question of violence as a matter for State policy, in a different political setting marked by the restoration of democracy and more active and committed participation by democratic governments in international conferences.

In the first phase, suitable conditions were generated for women to meet in homogeneous groups in which they could share and reinterpret experiences of great significance for their lives, against a social background which made people very sensitive to violence. In the second phase, cases of violence against women, especially domestic violence, were collected as a formal issue, while at the same time the social actors who would promote the matter and the organizations which would give it support and social strength were identified and established. In the third phase, the problem of domestic violence was decisively incorporated as a matter of public discussion and its institutionalization as a formal subject of public policy was begun. Intra-family violence -the new way of viewing domestic violence- goes beyond the social domain established in the previous phase and incorporates new institutional and political actors, thereby altering the positions and functions of the old ones.

\section{II}

\section{The emergence of the process}

As Pakman (1995, p. 296) rightly notes, social and cultural movements usually start with a more or less formalized set of conversations and social practices. "They do not usually start one fine day with a ritual declaratory founding event. Conversations and practices which are more or less devoid of any order, in areas which are not necessarily univocal and may sometimes even be contradictory, begin to produce forms of language capable of reflecting some particular area of human activities. At some moment, as a result of those processes and as part of the conversations, a reflexive action takes place through which these human groups see themselves reflected, define a field of interests, formalize their concerns and practices, forms of language and strategies, draw a border or frontier around themselves, set themselves objectives, share out functions and, ultimately, establish themselves as persons different from others".

The conditions conducive to the emergence of domestic violence as a public issue have been growing up gradually since the late 1970 s.

In the first few years of the military regime most of the population came face to face with violence in its various forms: violation of the physical integrity of persons, persecution, authoritarian attitudes, arbitrary actions, unemployment or poverty, and loss of social reference spaces. As in the case of women the repression took on clear sexual connotations, the population became more sensitive to women's vulnerability to sexual abuse.

The restriction of individual and collective liberties, together with the closure of spaces which had existed earlier - political parties, trade unions, neighbourhood associations- gave rise to a generalized climate of fear and inhibition which impeded the collective expression of the social trauma represented by the military coup.

At the end of the 1970s the indiscriminate repression applied up to then was slightly relaxed, and the Vicariate for Solidarity and the Academy of Christian Humanism ${ }^{2}$ stimulated the formation of

\footnotetext{
${ }^{2}$ The Academy of Christian Humanism was founded in November 1975 by the then Archbishop of Santiago, Cardinal Raúl Silva Henríquez, as "a response to the particularly difficult situation in which the Chilean intellectual community has found itself since the installation of the military regime in the country". This situation had led to the intervention of the universities by the new regime, involving the expulsion of thousands of professors, students and administrative personnel, the elimination of courses, changes in curricula, and limitations on research, teaching and extension activities. The Academy welcomes these professionals in its different Research Programmes and in its eleven Study Circles, among which is the Study Circle on the Status of Women (Academy of Christian Humanism, undated).
} 
new social organizations, circles of professionals and collectives for the defence of human rights which welcomed and facilitated the meeting of persons from the former social and popular organizations, political party militants, trade unionists and professionals.

Human rights organizations, people's organizations and non-governmental organizations (NGOs), which became increasingly numerous in the 1980s, became the spearheads for efforts to reconstruct the social fabric. In this task they received aid in the form of international cooperation for supporting the efforts being made in Chile to rebuild the social links that had been destroyed by the dictatorship.

The energy that had been blocked by violence and repression was restored in these areas thanks to the affective and emotional nature of the links that people generate within themselves, and it served to promote the collective expression of the traumatic experiences suffered and to foster action aimed at surviving and resisting the military regime.

The Vicariate for Solidarity stimulated the organization of soup kitchens, production groups and other collectives which were mainly made up of women, partly because women were seen as being more neutral as far as the political struggle was concerned and less closely involved in the confrontation that preceded the military coup. These organizations were imbued with the characteristics of the personal experiences of these women and were more flexibly adapted to their everyday rates of activity and responsibilities. In them, the women discussed questions relating not only to repression and political violence, but also to their everyday life. This set in motion the emergence into broad daylight of the different types of violence suffered by them, including violence inflicted on them by their spouses.

In these first moments, it was accepted that the political violence used against women had clear sexual overtones, and in these new organizations women talked about their experiences of domestic violence. However, they were far from interpreting the different forms of violence suffered by them as expressions of a single system which gives priority to men and subordinates and disempowers women. There was great resistance to the idea of putting domestic and sexual violence against women under the same concept as police violence, since such violence was interpreted basically as a product of the power relations between classes. It was necessary to establish new frames of interpretation with organized women's groups and new forms of organization in order to convoke, mobilize and involve women in collective action to deal with violence against women.

As noted by Muller and Surel (1998), whatever the reasons why a social phenomenon comes to be seen as a serious issue (increased frequency or unexpected nature of the cases involved, for example), it is essential that such phenomena should be interpreted or defined by the actors directly involved, who should prepare explanations and accounts of the problems experienced. This interpretation is not only supported by the weight of the material nature of social phenomena but is very often also made possible by the emergence of new interpretative norms for social and/or human matters.

In the case of the feminist and women's movement, the formulation of new frames of interpretation was the result of the relations between members of the international feminist movement and women's organizations inside Chile.

Exile became the most important link between the national and international expressions of the feminist movement, as well as a means for the dissemination of new ideas and forms of organization within the country. The critical experiences of women who had to leave the country because they were left-wing militants or companions of exiled persons and who had to relate with their companion and family in new circumstances made them sensitive to the ideas spread by the vigorous feminist movement between the mid-1970s and mid-1980s in Europe and the United States. The international feminist movement's rejection of the Chilean military dictatorship made it all the easier to progress from the struggle against the dictatorship to rejection of the subordinate position of women, with support for the resistance in Chile being combined with militancy in women's organizations. These feminist collectives, which were more flexible and less vertically organized than the political parties or trade unions, fostered the establishment of closer and fuller relations and provided their members with affective and psychological support. All this favoured a new interpretation of women's life experiences. Matters previously seen as private began to be reinterpreted from the point of view of discrimination against women and inequality between the sexes.

The establishment of the Study Circle on the Status of Women in 1977 was extremely important 
in terms of the formulation of new frames of interpretation and their dissemination in other organizations. The origins of the Circle lie in the relations of friendship and political sympathy that grew up between women who had been active members of left-wing political parties and/or were now working in human rights organizations or organizations designed to show solidarity with the less privileged sectors. At the time of its establishment they were also united by their great sensitivity to the situation of subordination and disadvantage suffered by women and their interest in embracing new ideas that reinterpret the relations between the sexes. Furthermore, the acceptance of the Circle in the Academy of Christian Humanism was a first recognition among those opposed to the dictatorship that the situation of women could be considered as a major object of study and social concern.

The Circle became part of the network of feminist organizations that began to grow up in Latin America and the Caribbean after the First Feminist Encounter in the Region (Bogotá, 1981), and its members participated in the international meetings on women that were held, beginning with the World Conference on the United Nations Decade for Women (Copenhagen, 1980). It also became the meeting point for women returning from exile. Its members oriented their activities towards other women, who were invited to take part in self-awareness groups where, as a form of testimony and with the support of others, they could share their ideas on the different forms of subordination and assert their desire for and commitment to the attainment of changes in the power relations between men and women. Such collective experience is essential in order to overcome the individual tendency to attribute painful experiences to casual circumstances or factors of a personal nature.

The spread of the new ideas within organizations such as the Commission on Women's Rights
(CODEM), the Working-Class Women's Movement (MOMUPO) and the solidarity-oriented organizations of the Vicariate gave rise to a lively debate between women who had already embraced those ideas and the rest of the members of those organizations. The interpretation of violence against women as an extreme expression of the male power that is present at all social levels, including left-wing and lower-class sectors, was considered to be in contradiction to the priority given to class inequalities and, furthermore, it was seen as a divisive move designed to distract women's attention from the main problem: the dictatorship. In some cases, when the conflict grew more acute the women who supported the new interpretations on discrimination had to leave the organizations and form their own collectives.

To sum up, in this first phase several different factors came together at the national and international levels, generating the conditions for the emergence of a new social movement that reinterpreted the life experiences and situations of women and their relationships with men. As we have seen, the conjunction of the features of the prevailing political context with the new organizational resources, collective dynamics and frames of interpretation provided fertile ground for the appearance of the movement against domestic violence. The relative slackening of the massive and indiscriminate repression that had marked the first years of the dictatorship and the international repudiation and isolation of the latter, together with the international support given to the opposition forces, facilitated the emergence of new organizations and collective dynamics aimed at furthering the rebuilding of the social fabric and the struggle against the dictatorship. The new frames of interpretation positing the existence of an unjust system of social relations between the sexes allowed women to reinterpret their experiences in terms of a new system of inequality and to commit themselves to changing those unjust relations between the sexes. 


\section{III}

\section{Formulating the issue of domestic violence and securing its inclusion in the public debate (1983-1990)}

From the mid-1980s on, the protest movement and popular resistance to the dictatorship and the spaces for action and participation against the dictatorial regime expanded gradually but steadily. Various different strategies were used in the struggle against the dictatorship, reflecting the different conceptions of the opposition forces on change and the recovery of democracy and their individual assessments of the power relations on the political scene.

In 1983, the mass social movement became highly visible: this was the year of outright protests and direct confrontation with the regime. After the attempt to assassinate Pinochet in 1986, however, this strategy gave way to negotiations by the parties in search of a political way out from the dictatorship. This culminated in the 1988 plebiscite, which resulted in a decision to put an end to the dictatorship and introduce a democratic regime within two years. By the end of the 1980s the resistance against the dictatorship took on a more political nature, in the traditional sense of the term. The parties began to play a more active part and fulfilled their traditional function as a bridge between society and the State, and they became the preferred place for dealing with the public issues that were to be considered on the agendas of the coming democratic governments.

The spread and formal establishment of the question of domestic violence as a public issue were influenced by the changes taking place in the political and social contexts.

By the end of the 1980s, after having originally been a problem raised and mobilized by women in order to make it more visible, check it and deal with its different forms, domestic violence began to win itself a space on the public agenda. The new political opportunities that opened up after the plebiscite and the imminent return of democracy eased its incorporation into that agenda, as well as the participation of new actors who came from other social fields and/or were active members of opposition political parties in the debate on the causes of the problem and private and public ways of solving it.

During this phase, a new political domain was constructed around sex discrimination. Its participants included various women's organizations, groups and collectives spreading a different discourse on discrimination and promoting new social practices to deal with it. The emergence of feminist NGOs played a central role in this. Their activities, aimed at disseminating new ideas on the real situation of women and relations between the sexes, within the narrow public spaces left open by the dictatorship, received international support, which helped to give continuity to the activities embarked upon. The feminist NGOs established relations with women from all walks of life, but especially those in an under-privileged situation: women from the lower urban strata, peasants and indigenous women.

Let us take a closer look at this process. Around 1983, the formulation of sex discrimination and domestic violence as social issues reached a level of visibility which reflected the emergence of a new collective concern, and it also made possible the formulation of a new frame of interpretation on discrimination against women, as well as more flexible forms of organization which favoured exchanges of views and discussions among women.

In 1983 the Study Circle on the Status of Women gave way to "La Morada" and the Centre for Studies on Women's Affairs, while in 1984 the Women's Information and Communication Service (ISIS) set up its regional headquarters in the country. Other important NGOs, such as the Casa de la Mujer in Valparaíso (1987) and the Instituto de la Mujer (1988) were also established from the mid-1980s on.

Within this new political domain generated around discrimination, a new subject -that of domestic violence- also took shape, linking together a 
number of organizations and persons interested in denouncing such violence and providing psychological and legal support for maltreated women. The participants in this new field of concern shared the conviction that it is necessary to strengthen the position of maltreated women, open up spaces for the expression of their pain, aspirations and expectations, and organize them on a collective basis as a preliminary step to transforming the relations between men and women. It was hard to distinguish institutional commitment from personal commitment, as the institutions and organizations active in this field were deeply impregnated with the characteristics of their members.

Social concern about violence was thus based on the existence of a larger political domain. The relation between the two was complex and changed over time. The political domain concerned with sex discrimination provided a frame of interpretation for actions against violence, while it also allowed this to be understood from a more systemic perspective as violence against women -as expressed at the beginning of this phase- and not just as cases of women who had been mistreated and beaten. At the same time it proposed a new way of tackling violence, based on the principles of self-awareness and the collective expression of painful experiences as part of the healing process. It also provided a network of relations and links between organizations and persons, to be used by those committed to the study of this problem.

This wider political domain, however, also had other priorities and demands for its own strengthening. Furthermore, the energy and time devoted to the struggle against the dictatorship diverted attention from the specific problem of domestic violence. Consequently, those committed to the study of this problem had to make an effort to attract attention and obtain support for their activities. In reality, they had to generate their own public among the persons and institutions active in the field of combatting sex discrimination, but their task was facilitated at the beginning by the fact that the differentiation of the problem and of ways of dealing with it was of great importance for the women's movement as a whole, as the topic created and strengthened links between women from different social strata: upper-, middleand lower-class women, professionals, activists or housewives. Sharing their experiences of the different forms of violence allowed all of them to over- come social barriers and reduce any misgivings about the possibility of one group imposing its ideas on another.

Initially, the women who entered this field were women who had arrived at this point by different paths that were not always mutually exclusive but shared as a common denominator their affective proximity to the problem: a proximity due to the fact that they had been witnesses of the use of violence against their mothers when they were children, they had suffered such violence themselves at the hands of their partners, or they had been deeply affected by the experiences of violence suffered by other women. They were all united by a sense of frustration and impotence which became a powerful source of energy once they had the opportunity to express and discharge their feelings collectively. The arrival of feminist foreign nuns was of fundamental importance for creating an awareness of the need to tackle the problem. Furthermore, in view of the high degree of legitimacy of the church at that time, the possibility of organizing themselves and participating in that social field represented a great stimulus for maltreated women.

As Valente (1994) shows, the assimilation of new and controversial ideas is facilitated when people with social prestige accept them. In order to accept new ideas, people do not only trust their own opinions but also take account of those of their friends and neighbours and of the most influential persons in their social environment, thus reducing the degree of uncertainty involved in the acceptance of such ideas.

Organizations and individuals played different roles in the field of domestic violence, and this strengthened the activities of each of them. ${ }^{3}$ Some groups specialized in dissemination work and in fos-

\footnotetext{
3 Outstanding in this field are feminist organizations with a political and movement-oriented approach (La Morada; La Casa de la Mujer in Valparaiso, for example); organizations engaged in the dissemination of information and the provision of training and support for the creation of networks (ISIS; La Morada); movements aiming to exert an influence in the political field (Movimiento de Mujeres por el Socialismo; Concertación de Mujeres por la Democracia); organizations that seek to establish links between women of different social sectors (Colectivo Chile-Canadá and La Morada, for example), and other organizations devoted to the dissemination of women's rights (RIDEM) and the establishment of links between the different actors (Movimiento por la Emancipación de la Mujer Chilena).
} 
tering sensitivity to this issue through campaigns. Others were responsible for furthering the organization of women in lower-class sectors. Some institutions provided support services, and finally, there were also organizations and persons engaged in generating greater knowledge and information on the problem.

Nor was there only a single type of leading figure. The different types of leadership increased in number in the process of formulating the problem of domestic violence, spreading its study into new fields, and generating the social force needed to sustain their tasks. Some figures were undisputed leaders because of their capacity for interpreting, defining and redefining the significance and implications of domestic violence from new perspectives and from the analysis of the accumulated experience. Others stood out because of their capacity to link together women from different sectors and to move smoothly between different organizations and institutions. The importance of some others lay above all in their links with other public spaces, such as those of human rights or political opposition, for example, while still others were noted for their assertiveness, energy, capacity for hard work and dedication.

The initiatives and forms of communication arose from different points, forming a communication network on domestic violence involving various types of women's organizations: feminist organizations, collectives from the lower-class sectors, and other organizations closer to political parties.

The quality and frequency of the links among those making up this network gave rise to a dense but flexible horizontal structure of relations which facilitated the communication and assimilation of new frames of interpretation and the generation of consensuses. This network was also marked by a climate of solidarity, mutual confidence (affective links) and cooperation in pursuit of a common objective.

The frequency and intensity of the links also fostered a change in the subjective definition of the everyday life of women. The groups they formed and their face-to-face communication with each other formed the necessary social basis for reaffirming the new feelings and definitions on violence (see Berger and Luckman, 1968). However, the nature of these links tended to cause this space to close in on itself, because it grew almost exclusively in terms of women who were suffering or had suffered situations of violence. Although this can be a positive feature when beginning to build up a political domain, it can become an obstacle when trying to open up to other sectors and actors. The political context of the dictatorship naturally helped to foster this tendency to form a closed group and obscured the possibility of seeking support or co-responsibility on the matter from other social actors or movements and still less from the public institutions.

As from 1987, the political situation in the country gradually changed. The many NGOs served as the nucleus for a political discussion space shared by the various forces that opposed the dictatorship and were struggling for the country's return to democracy. Various citizen initiatives were organized, among them the Asamblea de la Civilidad, which was the forerunner of the Concertación de Partidos por la Democracia and in which women took part and put forward their own ideas and demands.

The preparations for the 1988 Plebiscite and the subsequent participation in it further expanded this space for public debate, through the convergence of different discourses in a common arena. The formation of the Concertación de Partidos por la Democracia also made it possible to exchange ideas and interpretations on the situation in the country and the urgent problems that needed to be tackled, while the reincorporation of the feminists into the left-wing parties facilitated the access of proposals on discrimination against women and domestic violence into the newly recovered political party spaces.

In this setting, independent and militant feminists formed the Concertación de Mujeres por la Democracia, which reflected both the effort of women to bring the problems connected with the prevailing relations between the sexes into the public spaces now open, and the degree of visibility that women had acquired as political subjects. The Concertación de Mujeres generated a new and broader area of convergence, involving different frames of interpretation of the situation of women. Although many of the Concertación's members (some $50 \%$ of the Council of the Concertación) already acknowledged and were known for their feminist ideas, an equally large percentage still approached women's issues from the standpoint of their own fields of professional specialization or because of their parties' interest in gaining access to a new social base. 
The activists in the field of the fight against domestic violence gained access to the Concertación de Mujeres indirectly, through the most outstanding leaders in the political domain of sex discrimination. Their incorporation into the recently created Latin American and Caribbean Network Against Domestic and Sexual Violence, however, gave them a new international public space which made them more visible, gave them a leading role, and allowed them to gain priority for domestic violence over other issues also promoted by the feminists.

The establishment of the Chilean Network Against Domestic and Sexual Violence (REDCHVD), for its part, was to represent a higher degree of institutionalization of the coordination among organizations and persons active in this field. Finally, the organization of an international meeting on violence against women in the Santiago suburb of Conchalí not only brought the subject before public opinion but also highlighted the close links between national and international action.

Although the relations between those involved in the social field of violence -especially between professionals and experts on the one hand and middle-and lower-class women on the other- continued to be fluid, there were some tensions. At the end of this phase, the non-professional activists and the representatives of the urban lower-class sectors began to lose visibility and influence compared with the expert knowledge of the professionals and the political party militants. At the same time, many of those who had been known mainly as members of social movements or organizations also asserted their party membership. Thus, the collectively inspired social movement gradually ceased to be the main actor in the task of bringing the question of domestic violence into public spaces.

In this new social and political setting, the debate with other actors enriched the definitions and possibilities of action to deal with violence, while making them more complex. The broadening of the public debate and the experience accumulated in previous years fostered and at the same time reflected changes in the conception of domestic violence and the strategies proposed for dealing with it.

At first, domestic violence was interpreted as an expression (in the most extreme terms) of the unequal power relations between men and women. Within that interpretation, self-awareness and self-help groups became the main strategy for tack- ling that violence. They made it possible to make up for the psychological vulnerability of the victims, who were now able not only to communicate an experience suffered for a long time in silence, but also to stop being passive, helpless victims and instead feel that they were leading actors in their own lives within a collective process that united them with other women. Facing up to violence was then seen as a matter for women themselves, and it was considered that the solution of this problem depended largely on the level of organization and strength that women could generate.

Little by little, however, it became clear that not all women who suffered violence could become militants of the movement, so that it was necessary for the State to organize services -hopefully of adequate size and quality- to give individual attention to victims. It also became clear that merely becoming aware of the problem did not necessarily lead to changes in forms of behaviour and attitudes, which frequently called for more specialized support and thus went beyond the mere will for change. Feminist psychologists highlighted the complexity and density of the problem and showed that both men and women took part in the formation of violent situations, albeit with very different levels of power. The continued occurrence of these types of situations, in spite of women's higher level of awareness, aided a more systemic and dynamic interpretation of the problem and opened up a broader space for the participation of feminist professionals in two specific fields: those of legal matters and of psychology.

Furthermore, in order for the problem of domestic violence to begin to be considered as a public issue, it was necessary to open up a place in the discourse on violence raised by the forces opposing the military regime. This was achieved by emphasizing the similarities between domestic violence and violence in general, but this represented a challenge to the version of the causes of violence hitherto prevailing in that field, because it showed that domestic violence was not rooted exclusively in the class struggle but was also due to the unequal social relations between men and women.

The greater visibility achieved by women thanks to the new organizations and collective dynamics was accompanied from an early stage by the generation and dissemination of knowledge, in order to reveal the existence, magnitude and consequences of 
domestic violence and assert the fact that it was a public issue.

The social and political actions undertaken were backed up right from the start by the results of studies on this subject carried out both in Chile and abroad. At the same time, the continual increase in the demand for help by women who were victims of such violence was evidence not only of the magnitude of the problem but also of the social force underlying women's demands.

The changes in the conception of domestic violence and the new political opportunities favoured the expansion of the strategies proposed for tackling the problem: incorporation of the problem on the agendas of the political parties and institutions, negotiation with the political forces of the Concertación de Partidos por la Democracia and the future government, promotion of reforms to the law, and implementation of public services to tackle the problem. This made it necessary for the problem to be passed through the filter of expert opinion and the codes of the political parties.

In short, during these years domestic violence finally emerged as a social issue and gradually won for itself a place on the agenda of public problems.

At the start, the process was marked by the constant incorporation of new and varied groups of women with strong links among themselves, which made possible the growth and strengthening of a political domain. The expansion of opportunities for political activities favoured more open discussion of the public agenda and the future institutional agendas and forced the actors who had been formulating domestic violence as an important issue to learn new procedures, while also giving rise to pressures for the change or replacement of some groups and leaders. At the end of this phase, the women's movement opened up to new spaces and established links with actors from other political domains, thus facilitating the spread of the issue beyond its initial ambit.

\section{IV}

\section{The institutionalization of the problem of domestic violence at the level of the State}

With the restoration of democracy, the political setting changed and there was a decisive increase in the opportunities for spreading and discussing the new ideas generated in different social fields: women, human rights, indigenous problems, and young people. A new type of relationship was established between the State and society at large which was to give rise to new spaces for contacts and discussions among the State, political and social actors.

The Concertación de Mujeres por la Democracia presented the new government with an agenda on sex-related matters and specific proposals on how to tackle problems deriving from the positions of inequality suffered by women. It called for the establishment of a new institutional mechanism responsible for coordinating policies from the standpoint of gender (the National Women's Service SERNAM) and proposed that more women should be appointed to positions of authority.
The triumph of the Concertación de Partidos por la Democracia also opened up the State to persons who had been members of the opposition in the recent past and who had devoted part of their time to working in some NGO or other civilian organization, thus making such persons an important source of professionals and officials for the central government and some local levels of government: a situation which was particularly marked in the institutions which had only recently been set up. This shift of some of the actors who had conceived and formulated new public issues when they had been members of the public at large thus became an extremely important mechanism for allowing them to get inside the State institutions and design policies for tackling the issues they had raised.

In these circumstances, the political domains which had grown up in past decades underwent changes, both in the type of actors participating in them and in the relations between them. They now 
incorporated actors from other social and political fields, as well as State authorities and officials.

In the specific case of domestic violence, many of the women who had played leading roles in the previous phase entered SERNAM or formed part of pilot projects at the central or local level of government (in centres for aiding women who were victims of violence or in offices for women's affairs, for example). There were also other actors who gained greater importance and decision-making power: SERNAM, the Interministerial Commission on Intra-Family Violence, the corresponding programme of SERNAM, and the staff of centres for aiding maltreated women, the first of which were set up in the municipalities of Conchalí, Santiago, Huechuraba and El Bosque.

The new institutional, political and social actors thus incorporated approached this subject from broader institutional and ideological positions than in the past. Consequently, the links which had in the past mainly been between the women in NGOs and those in social organizations, as well as, to a lesser extent, with feminists in the political parties, now shifted to a new axis: the interaction between the State and society at large. Thus, the actors in civil society formed links with those in the institutions, especially SERNAM, the Interministerial Commission on Intra-Family Violence, and some municipalities, mainly through the Chilean Network Against Domestic and Sexual Violence (REDCHVD).

REDCHVD played a fundamental role in this new structure of the social domain of domestic violence. It represented the direct continuation of the conceptions, interpretations and feelings constructed in the previous decade. It was also the point of linkage with the international movement against violence and reception point for new ideas and proposals, and it continued to be based on the joint action of NGOs and grass-roots organizations. It asserted the importance of the organizational, political and ideological autonomy of the social actors vis-à-vis institutional interests (for example, any member of REDCHVD who entered the government had to withdraw from the Network in order not to compromise its independent status). Nevertheless, REDCHVD now operates in a different manner from that of the past: it organizes the relations between its various members in a more formal manner and gives priority to links with political and State actors in order to promote policies.
The priority that REDCHVD now gives to the adoption of laws or the implementation of services for maltreated women represents a change from the position of the old actors in the social domain of the struggle against violence. Since social problems must now pass through the filter of expert opinion before they can be institutionalized, the main positions in REDCHVD are no longer occupied by middleand lower-class women, who have made way for feminist professionals with an expert knowledge of legal matters and services. This has heightened the tensions among those active in this domain. The original promoters of the grass-roots organizations now feel left out as a result of the importance acquired by the professionals.

The establishment of the Interministerial Commission on Intra-Family Violence, for its part, which was set up by the Executive in 1992, is headed by SERNAM, and includes representatives of different sectors of government -the ministries of Health, Justice, Education, External Relations, Interior (Carabineros), Office of the Secretary-General of the Presidency of the Republic, and National Institute for Youth- opened up spaces within the State for the discussion of this newly recognized issue. SERNAM was responsible for persuading and convincing the different sectors of the urgency and importance of the issue and for facilitating its translation into the codes of each of these sectors. The invitation to REDCHVD to take part in that Commission reflected SERNAM's desire to maintain its links with civil society and increase its force and power of persuasion vis-à-vis the other sectors.

The Interministerial Commission on Intra-Family Violence gave its members the possibility of exchanging and modifying their conceptions on violence and relations between the sexes, of discussing the responsibility of their sectors in preventing and dealing with violence, and of identifying the resources that could be transferred to the programme against violence implemented by SERNAM. The presence of REDCHVD was an important factor in achieving these aims, as it could speak out about the significance of violence freely and independently of the logics of the individual sectors and could analyse it in the frame of interpretation of gender discrimination.

To sum up, the process of institutionalization of the problem of domestic violence within the 
State was initially propelled mainly by persons already committed to this matter, who mobilized their own personal networks to set in motion actions of an institutional nature. REDCHVD was the most valid and representative champion of women's interests in this respect vis-à-vis SERNAM, the government and the parliament, and it acted as a bridge between the already existing movement to combat violence against women and the new State institutions involved in this.

The general agreement and homogeneous conceptions, values and guidelines that characterized the social domain of the struggle against violence in the 1980s had been weakened by this time, thus giving rise to pressures for more specific agreements or for more general and abstract approaches in which the idea of violence as an expression of the power relations between the sexes had been diluted. Even so, this greater heterogeneity of actors and interpretations decisively aided in placing the issue within a broader public debate.

The definition of domestic violence as a policy object was easy to accept. The distance covered by other countries of the region in the discussion and adoption of laws against violence and the implementation of public services for this purpose legitimized women's policy proposals to the government and reaffirmed the State's responsibility for dealing with this problem.

\section{V}

\section{The preparation and processing of a law against violence}

The preparation, discussion and adoption of a law against violence meant that the problem must now gain access to a new agenda and a new institutional space: that of the legislature.

In this space, actors who were now active in it but had previously been close to the social movement created to deal with the problem of domestic violence sought to bring the issue onto the legislative agenda. Thus, for example, the female member of parliament who presented the first draft law had been an active participant in the women's movement in the 1980s, which was reflected both in her links with some feminist professionals for the preparation of the draft and in the frame of interpretation underlying the proposed law.

The incorporation of the issue into the legislative agenda and its subsequent progress therein made it necessary to redefine the problem under special conditions: expansion of the number of actors and positions (which increased the spaces and subjects of confrontation) and the application of new, strict rules which delimited the field in terms of discourses and procedures.

In view of the formal and specific nature of the legislative context, the actors must be specialized and must be familiar with the rules in order to recog- nize the limits that apply to their actions and know how to make use of the possible spaces for action. The legislature demands from its actors a style of discourse based strictly on arguments and subject to certain basic guidelines: the prevailing constitutional and legal principles, the accepted definition of the functions of a legislator, and the fundamental values on which the understanding of society is based. The actors are subject to certain demands in terms of dialogue, since this space is obviously one of confrontation.

These characteristics also mean that the relations with actors from other spheres are clearly subject to the logic of the legislature. In other words, all the demands or problems presented as inputs for the debate must conform strictly to the rules of parliamentary procedure.

Institutionalization in terms of the legislature means dealing with two areas of controversy. One is that of the different issues that are competing for a place on the agenda, by showing not only their existence and importance and the need for legislation on the matter, but also the urgent need to do so. A large part of the arguments of the members of parliament who were promoting the question of domestic violence were designed to prove that this problem could 
not be solved merely by generating and approving social programmes. Agreement was reached on this subject without too much resistance, and the Executive intervened to give the proposal a degree of urgency.

The second area of controversy was that of the confrontation between different versions of the problem. The frames of interpretation did not appear simultaneously but emerged gradually in the course of the process, as a function of the cultural conceptions and political interests of the actors.

In the case in question, there were three competing frames of interpretation: that of discrimination, that of human rights, and that of the family.

The first of these, which inspired the first draft law on the subject and was supported by the most progressive political sectors, held that women are the juridical good that is to be protected, and interpreted domestic violence as one expression of the global situations of discrimination and authoritarianism that women suffer in society. The second, which was based on the concept of human rights and made its appearance when the draft was being discussed in the Working Commissions of the Chamber of Deputies, was mainly concerned with the family and considered domestic violence as an offence against universal human rights; the main argument for this position was the need to comply with the international conventions signed by the government. Finally, the frame of interpretation based on the family, which emerged when the draft was being discussed in the Senate and was supported by the most conservative elements, considered that the family was the good

\section{VI}

\section{Conclusions}

In this article, we have analysed the process whereby, in the space of less than 25 years, an issue which was absent from Chilean and international debates and legislative agendas came to be a recognized social issue which has now given rise to a high level of consensus on the need to stamp it out as a social practice. This process was long enough to generate a political domain and give rise to new discourses on relations between the sexes. In this sense, that the State should protect, as this guaranteed the maintenance and sound health of society; the arguments in support of it made abundant reference to the consequences of violence in the home but did not refer to women as a subject of law. This process of confrontation between the different discourses was reflected in the change in the name of the law from "domestic violence" to "intra-family violence", indicating that it was the latter frame of interpretation which would prevail in the spirit of the law.

The different positions made use of their own types of strategies and resources: types of arguments, methods of exerting pressure, and utilization of sources of power (use of public opinion, powers of the Executive, etc.). The latter turned out to be an extremely important non-discourse-based resource. In addition, each of the positions changed, guided or modified the use of these resources as a function of new evidence, progress in the discussions, and the objectives considered to be most important at the time of the discussion, such as, for example, first of all securing agreement to legislate and then achieving consensus, in order to facilitate the continuity of the process.

The existence of different frames of interpretation slows down the processing and adoption of a law. Thus, the different and opposing positions in the Chamber of Deputies and the Senate ${ }^{4}$ on the problem of domestic violence made it necessary to use one of the established procedures: the intervention of the Executive to veto the law. This made it possible to get out of the stalemate and adopt a negotiated law representing a compromise between the different positions.

the formulation of the experience of violence as a public issue was also the history of the constitution

\footnotetext{
4 Among the most significant amendments made by the Senate in the draft law sent to it by the Chamber of Deputies were the weakening of the preventive measures, the incorporation of the concept of the degree of ill-treatment, and the decision not to set up special courts.
} 
of women as social subjects, of their organizations, and of their strategies for propelling the matter ahead in different political contexts.

Different phases were to be observed in this process, depending on the characteristics of the political and institutional system and the political opportunities offered by it, the different types of actors taking part, the organizational resources at their disposal, the feelings guiding the interpretations and actions of the actors, and finally, the different social settings in which the process took place. These different settings were governed by their own logics, which the actors had to deal with and respect if they wanted to influence or act in them.

Each of the phases was also marked by the particular structure assumed by the links between the actors. In the first phase, the efforts to construct the problem and the political domain organized around domestic violence gave rise to a relatively broad and dense network with a high degree of interconnectivity and with the presence of various important actors of high prestige. This network structure made it possible to generate rapid consensus on the interpretation of violence. Furthermore, the multi-centre nature of the network reflected greater democracy and a less hierarchical relationship in the links that were established. In the third phase, with the incorporation of institutional and political actors, the network became more differentiated, the links lost the dense and horizontal nature which had previously characterized them, so that they became more hierarchical, and reaching interpretative consensuses became more difficult and slower.

This article also highlights the dynamic and complex nature of this process, whose results were not and could not be determined in advance. Indeed, neither the way of interpreting domestic violence when the law was adopted, nor the final outcomes of the process were contained in its initial bases or in the initial political action of women. On the contrary, the interpretations and objectives changed and became more complex over time, as a function of the different actors who were becoming involved or were withdrawing from the process and the changes in the feelings that guided them.

To sum up, the article shows that public issues do not exist in their own right as objective entities, but are constructed by actors who take part in the different settings, in which they exchange and confront discourses based on different frames of interpretation.

(Original: Spanish)

\section{Bibliography}

Academy of Christian Humanism (no date): Folleto de difusión, Santiago, Chile (mimeo).

Berger, P. and T. Luckman (1968): La construcción social de la realidad, Mexico City, Amorrortu.

McAdam, D., J. McCarthy and M. N. Zald (eds.) (1996): Comparative Perspectives on Social Movements. Political Opportunities, Mobilizing Structures and Cultural Framings, Cambridge, Massachusetts, Cambridge University Press.
Muller, P. and I. Surel (1998): L'analyse des politiques publiques, Paris, Editorial Montchrétien.

Pakman, M. (1995): Redes: una metáfora para práctica de intervención social, in E. Dabas and D. Najmanovich (comps.), Redes. El lenguaje de los vínculos, hacia la reconstrucción y el fortalecimiento de la sociedad civil, Buenos Aires, Paidós.

Valente, T. W. (1994): Network Models of the Diffusion of Innovation, New Jersey, Cresskill. 